\title{
Diagnosis of deep vein thrombosis using 3D black-blood thrombus imaging (BTI): preliminary clinical experience
}

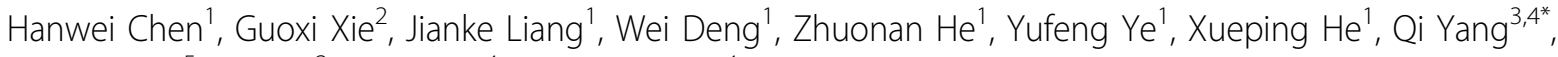 \\ Xiaoming $\mathrm{Bi}^{5}$, Xin Liu', Debiao $\mathrm{Li}^{4}$, Zhaoyang Fan ${ }^{4}$
}

From 19th Annual SCMR Scientific Sessions

Los Angeles, CA, USA. 27-30 January 2016

\section{Background}

Deep vein thrombosis (DVT) is a common but elusive illness that can lead to fatal pulmonary embolism and sudden death. Effective treatment of DVT requires accurate evaluation of thrombus distribution and stage. MRI is one of diagnostic imaging modalities for DVT, and two conventional methods are MPRAGE[1] and CE-MRV[2]. Recently, 3D T1-weighted variable-flipangle turbo spin-echo (SPACE) was proposed as a black-blood technique that permits more direct visualization of DVT[3]. However, signal suppression of tremendously slow venous blood flow remains a challenge for SPACE. The unsuppressed blood signal could be a confounder in thrombus detection[3]. We hypothesized that the 3D black-blood thrombus imaging (BTI) technique[4] that combines SPACE with DANTE black-blood preparation[5] (DANTE-SPACE) might address the above issue.

\section{Methods}

Experiment

The IRB-approved study was performed on a 3T scanner (Siemens TimTrio, Germany). DANTE-SPACE was first optimized on 8 healthy subjects (4 F $4 \mathrm{M}$, age $25 \pm 4$ ) and then tested on 12 patients (6 F $6 \mathrm{M}$, age $52 \pm 13$ ) with DVT. The optimized parameters for DANTE included: FA $15^{\circ}$, pulse trains 175 , RF gap $1 \mathrm{~ms}$, gradient $20 \mathrm{mT} / \mathrm{m}$. The parameters for SPACE included: 3D coronal imaging with a resolution of $1.1 \times 1.1 \times(1.1-1.3)$ $\mathrm{mm}^{3}$ (interpolated to $0.55 \times 0.55 \times[0.55-0.65] \mathrm{mm}^{3}$ ), $\mathrm{TR} /$ TE $650 / 9.8 \mathrm{~ms}$, turbo factor 40, GRAPPA 2 , scan time $\sim 4 \mathrm{~min}$. The scan was targeted to the thrombus region that was pre-determined by ultrasound within 3 days. Conventional SPACE, MPRAGE, and CE-MRV were conducted for comparison.

Table 1 Qualitative and quantitative analysis results for the comparison among DANTE-SPACE, SPACE, MPRAGE, and CE-MRV

\begin{tabular}{|c|c|c|c|c|c|c|c|c|c|}
\hline & $\begin{array}{c}\text { Score } \\
\text { (mean } \pm \text { std) }\end{array}$ & $\begin{array}{c}\text { Number of } \\
\text { thrombosed segment }\end{array}$ & $\begin{array}{l}\text { SE } \\
(\%)\end{array}$ & $\begin{array}{l}\text { SP } \\
(\%)\end{array}$ & $\begin{array}{l}\text { PPV } \\
\text { (\%) }\end{array}$ & $\begin{array}{l}\text { NPV } \\
(\%)\end{array}$ & $\begin{array}{l}\text { ACC } \\
(\%)\end{array}$ & $\begin{array}{c}\text { Diagnostic } \\
\text { agreement } \\
(\kappa \text { value / p })\end{array}$ & $\begin{array}{c}\text { Interobserver } \\
\text { agreement } \\
(\kappa \text { value } / \mathrm{p})\end{array}$ \\
\hline $\begin{array}{c}\text { DANTE-SPACE } \\
\text { (reader1)/(reader2) }\end{array}$ & $\begin{array}{r}(3.60 \pm 0.61) / \\
(3.70 \pm 0.46)\end{array}$ & $22 / 19$ & $\begin{array}{c}90.9 / \\
94.4\end{array}$ & $\begin{array}{c}97.8 / \\
97.9\end{array}$ & $\begin{array}{l}90.9 / \\
89.5\end{array}$ & $\begin{array}{c}97.8 / \\
98.9\end{array}$ & $\begin{array}{c}96.4 / \\
97.3\end{array}$ & $\begin{array}{c}(0.89 /<0.01) / \\
(0.90 /<0.01)\end{array}$ & $0.73 /<0.01$ \\
\hline $\begin{array}{l}\text { SPACE (reader1)/ } \\
\text { (reader2) }\end{array}$ & $\begin{array}{l}(3.22 \pm 0.88) / \\
(2.72 \pm 1.02)\end{array}$ & $20 / 20$ & $\begin{array}{c}86.4 / \\
83.3\end{array}$ & $\begin{array}{c}94.4 / \\
98.9\end{array}$ & $\begin{array}{c}78.3 / \\
92.9\end{array}$ & $\begin{array}{c}95.5 / \\
94.9\end{array}$ & $\begin{array}{c}92.0 / \\
94.6\end{array}$ & $\begin{array}{c}(0.88 /<0.01) / \\
(0.75 /<0.01)\end{array}$ & $0.63 /<0.01$ \\
\hline $\begin{array}{c}\text { MPRAGE (reader1)/ } \\
\text { (reader2) }\end{array}$ & $\begin{array}{c}(1.94 \pm 0.79) / \\
(2.61 \pm 0.90)\end{array}$ & $23 / 14$ & $\begin{array}{l}81.8 / \\
72.2\end{array}$ & $\begin{array}{c}98.8 / \\
94.7\end{array}$ & $\begin{array}{c}95.0 / \\
75.0\end{array}$ & $\begin{array}{c}96.7 / \\
96.7\end{array}$ & $\begin{array}{c}96.4 / \\
92.9\end{array}$ & $\begin{array}{c}(0.75 /<0.01) / \\
(0.78 /<0.01)\end{array}$ & $0.71 /<0.01$ \\
\hline $\begin{array}{l}\text { CE-MRV (reader1)/ } \\
\text { (reader2) }\end{array}$ & $\begin{array}{c}(3.81 \pm 0.42) / \\
(3.82 \pm 0.41)\end{array}$ & $22 / 18$ & - - & - - & - & - & - & - - & $0.81 /<0.01$ \\
\hline
\end{tabular}

${ }^{3}$ Xuanwu Hospital, Beijing, China

Full list of author information is available at the end of the article

(c) 2016 Chen et al. This is an Open Access article distributed under the terms of the Creative Commons Attribution License (http:// creativecommons.org/licenses/by/4.0), which permits unrestricted use, distribution, and reproduction in any medium, provided the original work is properly cited. The Creative Commons Public Domain Dedication waiver (http://creativecommons.org/publicdomain/ zero/1.0/) applies to the data made available in this article, unless otherwise stated. 

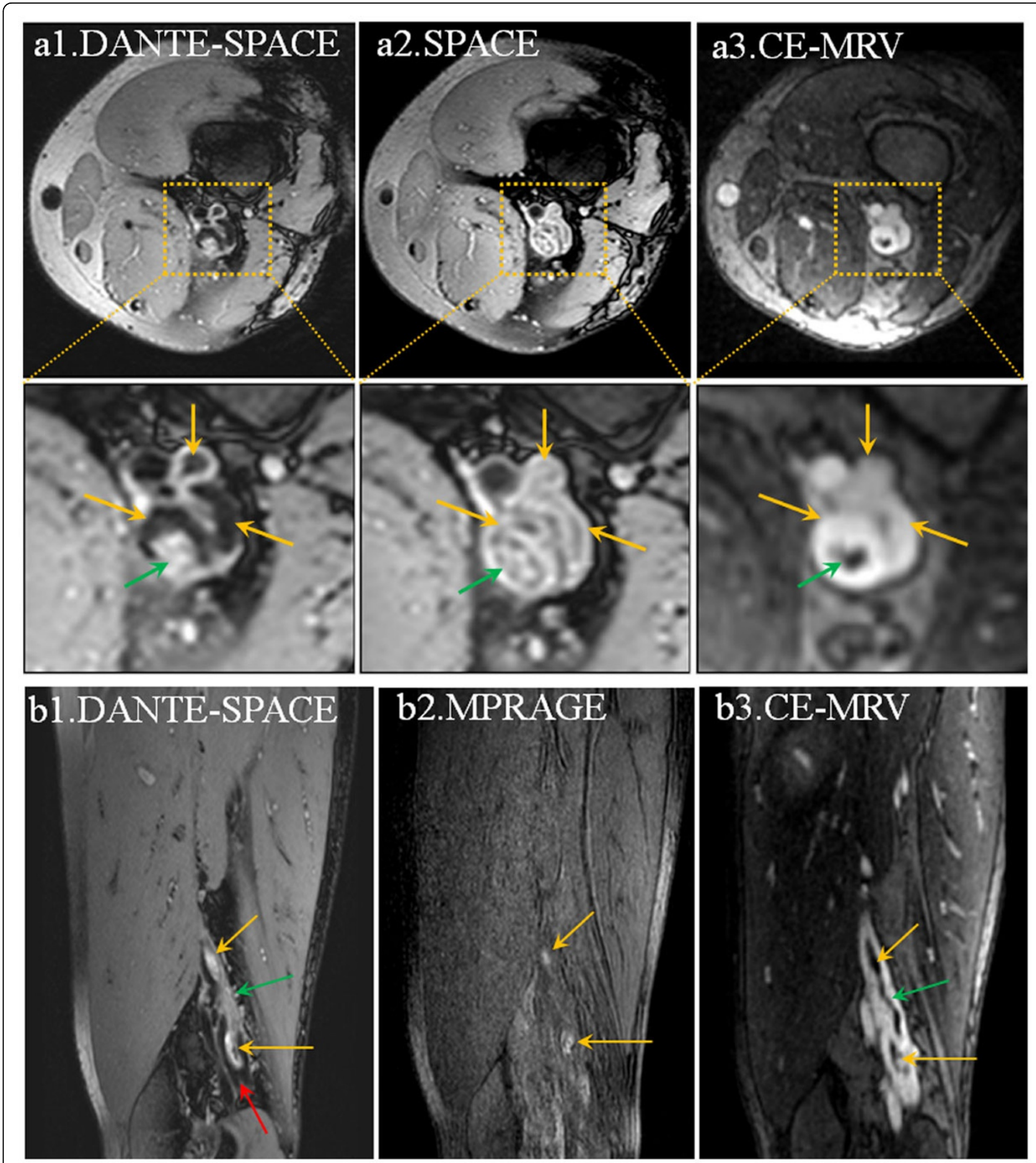

Figure 1 Representative images from a patient subject. The thrombus-mimicking venous blood signal with the SPACE sequence can be effectively eliminated by DANTE-SPACE (yellow arrows on a1\&a2). MPRAGE only detected the DVT in the acute or sub-acute stage because of short T1 relaxation time (yellow arrows on b2), while DANTE-SPACE depicted the DVT well regardless of the thrombus stage (yellow and green arrows on b1) as the venous blood flow (red arrow on b1) around the thrombus was effectively suppressed. The thrombus distribution matched well between DANTE-SPACE and CE-MRV (a1 vs. a3, b1 vs. b3). 


\section{Image Analysis}

Two radiologists (J. L. and Y. Y.) evaluated randomized images and gave the diagnosis confidence scores (1-poor, 4-excellent) to each technique independently. The sensitivity (SE), specificity (SP), positive and negative predictive values (PPV and NPV), and the accuracy (ACC) of DANTE-SPACE, SPACE, and MPRAGE were calculated using CE-MRV as the reference. The diagnostic agreement between DANTE-SPACE/SPACE/MPRAGE and CE-MRV and the interobserver agreement were conducted using Cohen $\kappa$ test.

\section{Results}

Compared to SPACE, DANTE-SPACE effectively nulled the residual blood that would otherwise be mistaken as part of thrombus (Fig. 1a1\&a2). In contrast to MPRAGE that is only sensitive to the acute or sub-acute thrombus (Fig. 1b1\&b2), DANTE-SPACE was able to depict the DVT regardless of the thrombus stage. DANTE-SPACE provided the highest diagnosis confidence score, when compared to SPACE and MPRAGE, and high SE, SP, PPV, NPV and ACC (Table 1).

\section{Conclusions}

DANTE-SPACE is a BTI technique providing excellent venous blood signal suppression and definitive thrombus detection. The preliminary patient study has demonstrated that the technique may outperform SPACE, MPRAGE and potentially become a noncontrast alternative to CE-MRV in the diagnosis of DVT.

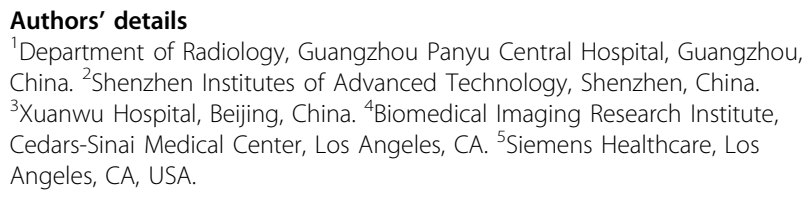

Published: 27 January 2016

\section{References}

1. Moody, et al: Radiol 1998, 209:349-355.

2. Arnoldussen C, et al: Phlebology 2014, 29:119-124.

3. Treitl, et al: Invest Radiol 2015, 50:401-408.

4. Fan, et al: ISMRM 2015, p0295.

5. Li L, et al: MRM 2012, 68:1423-1438.

doi:10.1186/1532-429X-18-S1-Q58

Cite this article as: Chen et al:: Diagnosis of deep vein thrombosis using 3D black-blood thrombus imaging (BTI): preliminary clinical experience. Journal of Cardiovascular Magnetic Resonance 2016 18(Suppl 1):Q58.
Submit your next manuscript to BioMed Central and take full advantage of:

- Convenient online submission

- Thorough peer review

- No space constraints or color figure charges

- Immediate publication on acceptance

- Inclusion in PubMed, CAS, Scopus and Google Scholar

- Research which is freely available for redistribution

Submit your manuscript at www.biomedcentral.com/submit
C BioMed Central 